\title{
A divulgaçáo do conhecimento em terapia ocupacional no Brasil: um retrato nos seus periódicos
}

\author{
Roseli Esquerdo Lopes ${ }^{\mathrm{a}}$, Maria Luiza Mangino Cardoso Duarte ${ }^{\mathrm{b}}$, Beatriz Prado Pereira ${ }^{\mathrm{c}}$, \\ Fátima Corrêa Oliverd, Ana Paula Serrata Malfitano ${ }^{\mathrm{a}}$ \\ aDepartamento de Terapia Ocupacional, Universidade Federal de São Carlos - UFSCar, São Carlos, SP, Brasil. \\ bUniversidade Federal de São Carlos - UFSCar, São Carlos, SP, Brasil. \\ 'Departamento de Terapia Ocupacional, Universidade Federal da Paraíba - UFPB, João Pessoa, PB, Brasil. \\ ${ }^{\mathrm{d}}$ Departamento de Fisioterapia, Fonoaudiologia e Terapia Ocupacional, Universidade de São Paulo - USP, \\ São Paulo, SP, Brasil.
}

\begin{abstract}
Resumo: Trata-se de apresentar e discutir os resultados de uma pesquisa que tomou como objeto a produção bibliográfica publicada, entre 1990 e 2014, nos Cadernos de Terapia Ocupacional da UFSCar e na Revista de Terapia Ocupacional da USP. Os objetivos foram caracterizar a produção em relação a ano de publicação, autores, instituições dos autores, área e subárea, categoria do texto e presença do termo "terapia ocupacional" ou correlato no título, no resumo ou nas palavras-chave e, com isso, criar um banco de dados virtual para sistematizar essa produção, que compõe parte considerável das publicações de terapeutas ocupacionais brasileiros. Com a reunião e organização de dados referentes a todos os volumes dos periódicos no período, foram incluídos neste estudo 881 textos e pode-se afirmar que esse número vem aumentando de modo importante, especialmente a partir de 2006. Mais de $60 \%$ dos textos são da área de terapia ocupacional e duas de suas subáreas se apresentaram com maior destaque: "saúde mental" e "fundamentos". Foram arroladas 254 instituições de vínculo dos autores, sendo que as de Ensino Superior têm maior presença, notadamente as públicas. Foram identificados 1.404 diferentes autores, $85,8 \%$ mulheres, e a absoluta maioria é de terapeutas ocupacionais. Em ambos os periódicos mais de $80 \%$ dos autores publicaram apenas um texto e poucos (entre 5,3\% e 3,2\%) publicaram cinco ou mais trabalhos. Tais dados são preocupantes com relação à institucionalização acadêmica da terapia ocupacional no Brasil, pois a existência de publicações é condição necessária, mas não suficiente, para o diálogo e construção acadêmicos.
\end{abstract}

Palavras-chave: Terapia Ocupacional, Periódicos, Publicações de Divulgação Científica, Conhecimento.

\section{Knowledge dissemination in occupational therapy in Brazil: a portrait in its journals}

\begin{abstract}
We present and discuss the results of a survey that took as an object the papers published between 1990 and 2014, in the Cadernos de Terapia Ocupacional da UFSCar (Occupational Therapy UFSCar Journal) and in the Revista de Terapia Ocupacional da USP (Occupational Therapy Journal of USP). The objectives were to characterize the production according to the publication year, authors, institutions of the authors, area and subarea, text category and the presence of the term "occupational therapy" or correlate in the title, abstract or keywords. Through this it was created a virtual database to systematize this production, which constitutes a considerable part of the Brazilian occupational therapists publications. With the data gathering and organization regarding all the journals volumes
\end{abstract}

Autor para correspondência: Roseli Esquerdo Lopes, Laboratório METUIA, Universidade Federal de São Carlos, Rodovia Washington Luiz, Km 235, CP 676, CEP 13565-905, São Carlos, SP, Brasil, e-mail: relopes@ufscar.br

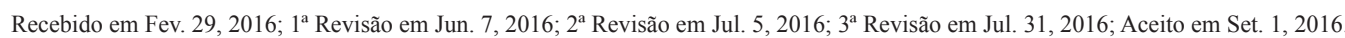


in the period, there were included in the study 881 texts, and this number has increased importantly, especially since 2006 . Over $60 \%$ of the texts are from the occupational therapy area, and two of its subareas were present with greater prominence: "mental health" and "fundamentals". There were enrolled 254 institutions of origin of the authors, in which the Higher Education highlights, notably the public universities. There were identified 1404 different authors, $85,8 \%$ were women, being the vast majority occupational therapists. In both journals, more than $80 \%$ of the authors published only one text, and few (between $5.3 \%$ and $3.2 \%$ ) published five or more. Such data is worrying regarding the academic institutionalization of Brazilian occupational therapy, since the publications is a necessary condition, but not enough, for dialogue and academic construction.

Keywords: Occupational Therapy, Periodicals, Publications for Science Diffusion, Knowledge.

\section{Introdução}

Este trabalho foi realizado conjuntamente por parte da equipe do Laboratório METUIA do Departamento de Terapia Ocupacional e do Programa de Pós-Graduaçáo em Terapia Ocupacional da Universidade Federal de São Carlos (UFSCar), durante o segundo semestre de $2014 \mathrm{e}$ o ano de 2015.

Desde 2010, com a implantação do Programa de Pós-Graduação em Terapia Ocupacional na UFSCar (MALFITANO et al., 2013), temos nos deparado com a proposiçáo de estudos que, para serem realizados, demandam o levantamento da produção científica em torno de diferentes temáticas articuladas à terapia ocupacional, tomando-se a coleção de volumes dos periódicos Cadernos de Terapia Ocupacional da UFSCar e da Revista de Terapia Ocupacional da USP. Apenas no Laboratório METUIA/UFSCar, que integra a linha de pesquisa "Redes Sociais e Vulnerabilidade" do referido programa, foram pelo menos 13 dissertaçôes que incluíram tal levantamento entre 2010 e 2015, além de pesquisas de iniciaçáo científica, de doutorado e trabalhos de conclusão de curso.

Certamente, esses levantamentos, de modo geral, são complementados por outros, em diferentes bases de dados acadêmicas; todavia, quando se trata de tomar a experiência nacional, e muitos estudos o fazem, o foco tem sido esses periódicos, a fim de retratar a literatura produzida pela terapia ocupacional.

Ao mesmo tempo, a experiência de parte das autoras na proposição e na elaboração desses periódicos, e na editoria de um deles, bem como as tarefas no âmbito da pesquisa e da pós-graduação em um dos grupos de trabalho da Rede Nacional de Ensino e Pesquisa em Terapia Ocupacional (RENETO) e de seus eventos correlatos, também têm imposto questionamentos em torno dos compromissos acadêmicos e científicos dos terapeutas ocupacionais no Brasil (LOPES; MALFITANO, 2009; LOPES et al., 2010; LOPES et al., 2014). Notadamente, há tal questionamento por parte daqueles que se dedicam à pesquisa na área, com a divulgação e a circulação dos resultados de seus estudos no âmbito da terapia ocupacional, assim como com a leitura desses trabalhos pelos terapeutas ocupacionais em geral, ou seja, com a necessidade de acessar e discutir, de "consumir" pesquisa, conhecimento, reflexóes, teorias (ou aportes epistêmicos) e práticas terapêutico-ocupacionais.

Em decorrência desses diversos fatores, em 2014, nos propusemos a constituir um banco de dados, de maneira a sistematizar toda a produção das duas revistas indexadas da área de terapia ocupacional no Brasil, os Cadernos de Terapia Ocupacional da UFSCar e a Revista de Terapia Ocupacional da USP, banco este a ser utilizado e atualizado continuamente por estudantes que vão se integrando à área, reunindo considerável parte das publicaçóes feitas pelos terapeutas ocupacionais brasileiros, oferecendo dados sobre essa produçáo, agregando elementos que, articulados a necessidades e/ou interesses específicos, venham a possibilitar linhas de reflexão quanto a esses produtos ${ }^{1}$.

\section{Método}

Inicialmente, foram reunidos, em formato impresso e eletrônico, todos os volumes e números da Revista de Terapia Ocupacional da USP2 e dos Cadernos de Terapia Ocupacional da UFSCar ${ }^{3}$.

A Revista de Terapia Ocupacional da USP, proposta por um grupo de docentes do Curso de Graduação em Terapia Ocupacional da Faculdade de Medicina da Universidade de São Paulo, no final da década de 1980, publicou o seu primeiro número em agosto de 1990; o periódico Cadernos de Terapia Ocupacional da UFSCar, igualmente lançado em 1990, no mês de maio, resultou da iniciativa de docentes da área de terapia ocupacional do antigo DEFITO - Departamento de Fisioterapia e Terapia Ocupacional (a partir de 1996, dois departamentos distintos) da UFSCar. 
Assim, o período considerado incluiu textos ${ }^{4}$ desde os primeiros volumes dos dois periódicos, de 1990, aos últimos volumes no ano de 2014. Foram excluídos da análise os editoriais, os suplementos publicados $^{5}$ e os resumos de teses e dissertaçóes.

Paralelamente, criou-se, para cada uma das revistas, uma planilha de dados por meio do Programa Excel $^{\circledR}$, na qual os textos foram arrolados sequencialmente por ordem temporal de publicação e foram incluídas informaçóes sobre ano de publicação, meio de acesso (impresso e/ou on-line), volume/número, autores, graduação dos autores, titulação dos autores, instituiçóes dos autores, cidade/estado vinculados às instituiçôes dos autores, título do texto, área, subárea e temática da produção, categoria do texto, palavras-chave, grupo populacional/faixa etária para o qual se voltava o texto, método/metodologia referidos, presença ou náo do termo "terapia ocupacional" ou correlato ${ }^{6}$ no título, no resumo ou nas palavras-chave, e a menção ou não à fonte de financiamento. Tais itens ofereceriam os dados a serem armazenados num banco de dados virtual; uma parte deles foi contabilizada, discutida e analisada para fins deste artigo.

A fim de manter uma coerência interna no preenchimento da planilha, a equipe discutiu os critérios a serem utilizados pelas pesquisadoras para, a partir da leitura dos títulos, palavras-chave e cada um dos resumos, incluírem-se informaçóes que requeriam alguma categorização, como, por exemplo, área e subárea.

No item "titulação dos autores", foram elencadas todas as titulaçôes dos autores e coautores, quando estas eram explicitadas, o que não foi uniforme durante um grande período em ambos os veículos; o mesmo ocorreu com relação à "graduação".

No que tange ao item "área", depois de um primeiro levantamento e de sua discussão, foram criadas denominaçóes de maneira a reunir um maior número de textos em cada uma delas, a saber: Terapia Ocupacional, Saúde, Saúde/Reabilitação, Política, Epistemologia, História, Educação, Assistência Social, em ordem decrescente de frequência nos resultados. A definiçáo da área dos textos foi realizada tomando-se o título, as palavras-chave e o resumo dos mesmos. Destaca-se que, ao aparecer o termo "terapia ocupacional" (ou algum correlato), em pelo menos um desses três itens, a área foi definida como sendo de terapia ocupacional; por outro lado, caso esse critério náo fosse cumprido, os textos eram classificados no escopo de outra área. Vale ressaltar que a produção na área de terapia ocupacional era o que se focalizava.
Quanto ao item "subárea”, esta foi estabelecida apenas para os textos da área de terapia ocupacional; as subáreas foram também definidas de modo a reunir um maior número em cada uma delas, quais sejam, em ordem alfabética: Contextos Hospitalares, Desenvolvimento Infantil, Disfunção Física, Educação, Formação, Fundamentos, Gerontologia, Reabilitação (com exceção daqueles afetos à Reabilitação Psicossocial, que foram enquadrados na subárea de Saúde Mental), Saúde Coletiva, Saúde Mental, Saúde do Trabalhador, Terapia Ocupacional Social e Trabalho.

A seguir, apresentamos e discutimos os principais resultados encontrados.

\section{Resultados e Discussão}

\subsection{Distribuição no tempo}

Como se pode verificar na Figura 1, o número de textos publicados por ano na Revista de Terapia Ocupacional da USP variou de cinco (o mais baixo, em 1999) a 39, o mais alto, em 2014, não tendo havido publicação nos anos de 1993, 1994 e 1995. O mesmo aconteceu nos Cadernos de Terapia Ocupacional da UFSCar, em 1994, 1995 e 1999, sendo que o ano de 1997 foi o de menor número de textos publicados, com cinco, e o de 2014, aquele com o maior número, totalizando 84 .

Até 2011, a Revista de Terapia Ocupacional da USP quase sempre teve um número maior de textos publicados que os Cadernos de Terapia Ocupacional da UFSCar (com exceção dos anos de 1996 e 2001). Entretanto, em 2012, ocorre uma mudança nessa tendência, com um crescimento maior do número de textos publicados pelos Cadernos, que teve um aumento de $109 \%$ entre 2009 e 2010 , de $30,4 \%$ em 2011, de 56,7\% em 2012, de 40,4\% em 2013 e de 27,3\% em 2014. Desde 2005, a Revista de Terapia Ocupacional da USP manteve uma tendência anual de crescimento, com exceção do ano de 2013.

Os dois periódicos passaram por distintas reformulações no período em estudo (do layout à composição de seu conselho editorial, por exemplo). No entanto, a partir de meados dos anos 2000, essas modificações são mais substanciais, no sentido de uma maior profissionalização na sua edição, o que foi percebido mais precocemente na Revista de Terapia Ocupacional da USP, com sua indexaçáo na base LILACS - Literatura Latino-Americana e do Caribe em Ciências da Saúde, ainda nos anos $1990^{7}$, e em 2003, quando passou a contar com o apoio do Conselho Regional de Fisioterapia e Terapia Ocupacional da Terceira Região (Estado de São 
a Cadernos UFSCar a Revista USP

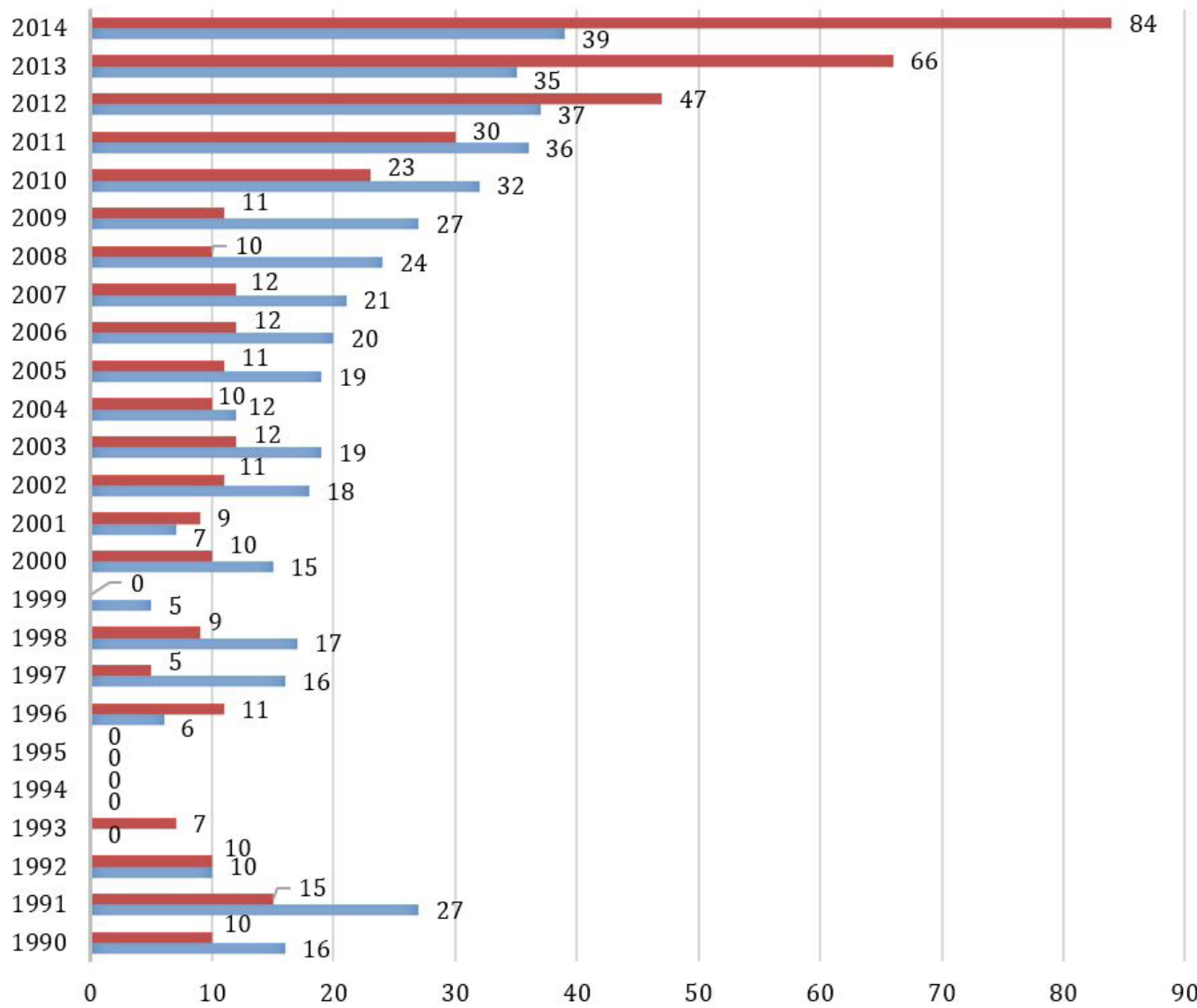

Figura 1. Número de textos publicados por ano e periódico, 1990-2014. Fonte: Revista de Terapia Ocupacional da USP (1990-2014) e Cadernos de Terapia Ocupacional da UFSCar (1990-2014), elaboração das autoras.

Paulo), o CREFITO-3, que passou a disponibilizar o conteúdo da revista no seu sítio na rede mundial de computadores. Em 2008, em um sítio próprio da USP, na rede mundial de computadores, seu conteúdo passou a ser disponibilizado unicamente no formato eletrônico (on-line). Com relação aos Cadernos de Terapia Ocupacional da UFSCar, a mesma indexação só veio a ocorrer em 2012, acompanhada de maiores mudanças com relação à melhor qualificação acadêmica ${ }^{8}$, à composição do seu conselho editorial, à política das seçóes, ao seu layout e à disponibilização on-line de todo o seu acervo, dentre outras medidas.

Essas mudanças vêm repercutindo no aumento do número de textos publicados, aliadas, provavelmente, ao incremento da titulação de mais docentes da área de terapia ocupacional (EMMEL; LANCMAN, 1998; LOPES et al., 2010); ao aumento do número de Instituições de Ensino Superior (IES) do setor público com curso de graduação em terapia ocupacional (PAN; LOPES, 2016), ao crescimento do número de pesquisadores voltados para área (LOPES et al., 2010) e de sua inserção como orientadores no sistema de pós-graduação no Brasil (LOPES et al., 2014), dentre outros aspectos.

\subsection{Classificação dos textos}

Foram contabilizados 458 textos na Revista de Terapia Ocupacional da USP, classificados, conforme informado pelo periódico, o que é trazido pela Tabela 1.

Nos Cadernos de Terapia Ocupacional da UFSCar, obtivemos uma quantidade de 477 textos, sendo 52 resumos de dissertaçóes e teses que não foram analisados, bem como três artigos, por não apresentarem resumo. Desse modo, os 425 textos reunidos, de 
Tabela 1. Classificação dos textos publicados por periódico, 1990-2014.

\begin{tabular}{|c|c|c|c|}
\hline Classificação do Texto & $\begin{array}{l}\text { Revista de Terapia } \\
\text { Ocupacional da USP }\end{array}$ & $\begin{array}{l}\text { Cadernos de Terapia } \\
\text { Ocupacional da } \\
\text { UFSCar }\end{array}$ & TOTAL \\
\hline Artigos / Artigos Originais & 411 & 318 & 729 \\
\hline Relatos de Projetos / Relatos de Experiência & 21 & 47 & 68 \\
\hline $\begin{array}{l}\text { Pontos de Vista / Debates / Artigos de } \\
\text { Reflexão / Ensaio ou Artigos de Atualização }\end{array}$ & 20 & 32 & 52 \\
\hline $\begin{array}{l}\text { Artigos de Revisão e/ou Atualização da } \\
\text { Literatura }\end{array}$ & 05 & 24 & 29 \\
\hline Comunicações Livres / Comunicação Breve & 01 & 4 & 5 \\
\hline TOTAL & 458 & 425 & 883 \\
\hline
\end{tabular}

Fonte: Revista de Terapia Ocupacional da USP (1990-2014) e Cadernos de Terapia Ocupacional da UFSCar (1990-2014), elaboração das autoras.

acordo com os dados trazidos pela própria revista, foram distribuídos como demonstra a Tabela 1 .

A classificação dos textos pelos periódicos variou de maneira importante, sendo que algumas dessas classes foram pouco encontradas, como, por exemplos, "Comunicação", "Comunicação Breve" ou "Comunicação Livre". Ainda, houve uma variação em torno do que se denominou "artigo", sendo que, até 2013, todos os textos da Revista de Terapia Ocupacional da USP eram assim denominados, tendo havido, posteriormente, em 2014, uma classificação interna entre os artigos de pesquisa ou original, de revisão e de atualização, a qual se mantém. Nos Cadernos de Terapia Ocupacional da UFSCar, desde 1990, havia uma diferenciação entre os tipos de textos e a atual classificação foi estabelecida em 2011.

\section{3 Áreas das temáticas}

A Figura 2 ilustra a área a que pertencem cada um dos 458 textos analisados na Revista de Terapia Ocupacional da USP, sendo que 280 publicaçôes são da área "Terapia Ocupacional" (62,7\%); 125 da "Saúde"; 26 textos englobavam o tema da saúde com um foco na reabilitação, sendo considerados da área "Saúde/Reabilitação"; além disso, foram registrados sete textos na área da "Assistência Social"; seis de "Políticas Públicas"; cinco de "História"; quatro na de "Educação", e um na de "Epistemologia". Por fim, cinco foram categorizados como "Outros", incluindo um de "Psicologia", um de "Trabalho" e dois de "Adaptaçáo Transcultural".

Já nos Cadernos de Terapia Ocupacional da UFSCar, dentre as 425 produçóes reunidas, foram classificados 306 textos (72,3\%) como da "Terapia Ocupacional”; 78 da "Saúde" e outros 13 também da saúde, mas com um foco nas questốes da reabilitação, ou seja, "Saúde/Reabilitação"; ainda, 12 textos articulavam temáticas da "Assistência Social"; dez da "Educação", enquanto outros dois voltavam-se para questôes do âmbito da "História" e um do "Trabalho" (como dito anteriormente, três textos não foram analisados por seus resumos não estarem disponíveis).

Uma reflexão que se coloca é a razão pela qual um volume de textos, entre cerca de $30 \%$ a $40 \%$ da produção nacional dos periódicos que se voltam para a área, não demonstrem, em seus títulos, palavras-chave e resumos, que têm como um dos seus focos a própria terapia ocupacional. Isto, talvez, decorra dos autores terem considerado desnecessária essa demarcação, visto serem textos apresentados em periódicos da área. Note-se que essa não identificação pode comprometer sua recuperação por diferentes mecanismos de busca ou bases de dados. Além disso, de modo aleatório e que, portanto, entra aqui como um aspecto a ser melhor trabalhado, diversos dos textos que mencionavam a terapia ocupacional, de fato, não tratavam desse tema.

A absoluta maioria dos autores é terapeuta ocupacional, sendo que autores com uma outra graduação ainda precisam ser conquistados pelos periódicos. Demonstrar e ser reconhecido como estando na área da saúde e/ou da saúde/reabilitação (integrando 32\% dos textos na Revista de Terapia Ocupacional da USP e 21\% nos Cadernos de Terapia Ocupacional da UFSCar) seria suficiente para a visibilidade da produção de conhecimento na área?

\subsection{As subáreas dos textos da área de terapia ocupacional}

Dos 280 textos identificados como da área de "terapia ocupacional" apresentados na Revista de Terapia Ocupacional da USP, destacam-se, em ordem decrescente, as subáreas de "saúde mental", "fundamentos”, "formação", "terapia ocupacional 


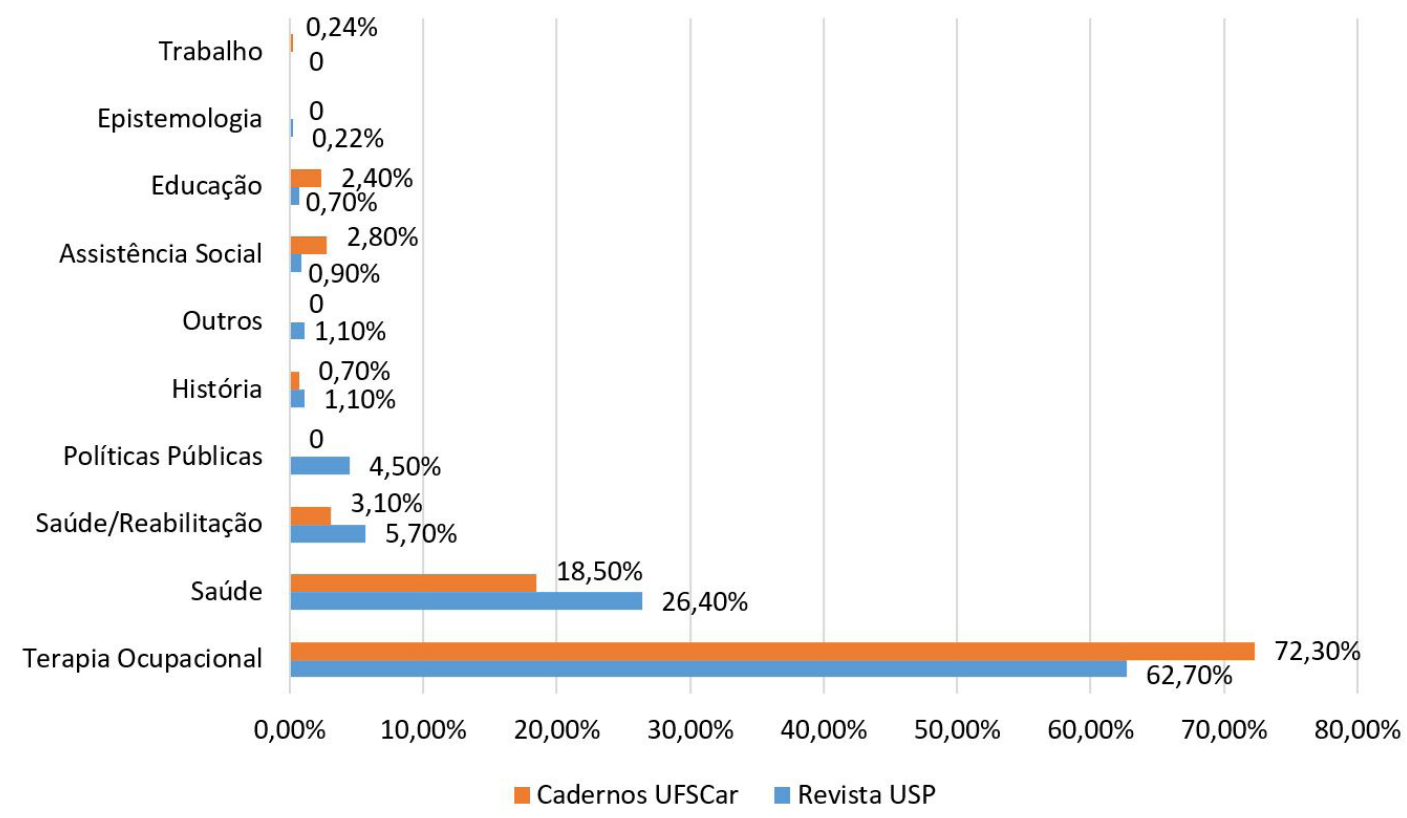

Figura 2. Áreas temáticas dos textos publicados pelos periódicos, 1990-2014. Fonte: Revista de Terapia Ocupacional da USP (1990-2014) e Cadernos de Terapia Ocupacional da UFSCar (1990-2014), elaboração das autoras.

social", "reabilitação" e, posteriormente, "gerontologia", "desenvolvimento infantil" e "contextos hospitalares", com o mesmo número de artigos. Também se observaram textos em "saúde coletiva", "educaçáa", abordagem da "disfunção física", "saúde do trabalhador" e "trabalho".

Os 306 textos da área "terapia ocupacional" dos Cadernos de Terapia Ocupacional da UFSCar foram, igualmente, distribuídos em subáreas e, em ordem decrescente, observa-se maior número deles sobre "fundamentos", em igual número aqueles sobre "formação" e "saúde mental", seguidos daqueles sobre "reabilitação", em igual número daqueles relacionados aos "contextos hospitalares". Em seguida, estão as publicaçóes que articulavam temáticas da "terapia ocupacional social", do "desenvolvimento infantil", da "disfunção física", da "saúde coletiva", da "saúde do trabalhador", da "educação" e, finalmente, outros textos tendo como subárea a "gerontologia".

Posteriormente, foram definidas as temáticas de cada uma dessas publicações, porém não foram criadas novas categorias para sua classificação, uma vez que os temas eram muito diversificados. Essa informação compóe um banco de dados que pode ser objeto de outras pesquisas.

$\mathrm{Na}$ Figura 3, apresenta-se a representação gráfica da distribuição dos textos nas subáreas.

\subsection{Instituição de vínculo dos autores}

Para compreender parte dos desafios e compromissos em torno da produção e divulgação do conhecimento em terapia ocupacional no Brasil, uma das articulaçôes possíveis é apreender o vínculo institucional dos autores e coautores dos textos, que compóem boa parte da trajetória de divulgação científica entre nós. Os autores e coautores dos textos eram docentes, estudantes de graduação e pós-graduação, profissionais e gestores de serviços de atenção. Não foi possível realizar uma classificação mais acurada porque a apresentação dos autores foi modificada ao longo do período estudado.

Sabe-se que, no Brasil, embora não apenas, a pesquisa e a produção de conhecimento estão estritamente ligadas às IES, notadamente às públicas, por estas reunirem melhores condiçôes para o desenvolvimento dessa dimensão do trabalho acadêmico, uma vez que o contrato docente prevê uma carga horária para tanto. Ao mesmo tempo, a contratação de terapeutas ocupacionais para o ensino na área sempre esteve bastante subordinada ao setor privado das IES, no qual têm sido maioria os cursos de graduação, embora venhamos assistindo a uma mudança nesse cenário desde o final da primeira década dos anos 2000 (PAN; LOPES, 2016).

Na Revista de Terapia Ocupacional da USP, foram 123 diferentes instituiçôes que compuseram 


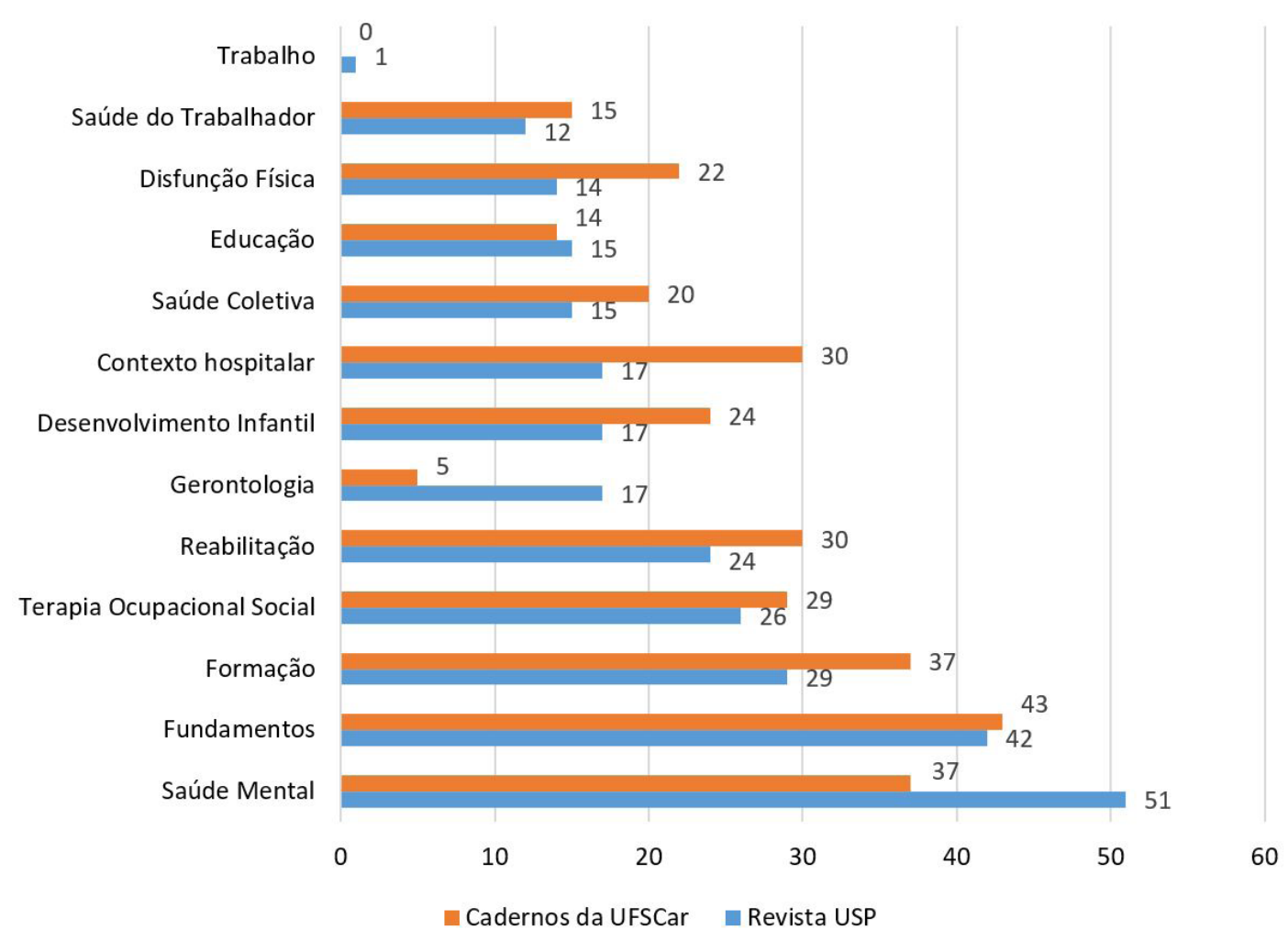

Figura 3. Subáreas temáticas dos textos publicados pelos periódicos, 1990-2014. Fonte: Revista de Terapia Ocupacional da USP (1990-2014) e Cadernos de Terapia Ocupacional da UFSCar (1990-2014), elaboração das autoras.

a vinculação dos autores dos textos considerados, sendo que, com relação a 11 destes, as instituições não puderam ser definidas. A preponderância das IES é notável, tendo sido relacionadas 67 diferentes IES, sendo 28 públicas e 32 privadas, num conjunto de 60 nacionais e sete estrangeiras.

Porém, se nos detivermos nas instituiçôes que aparecem com pelo menos dez autores em todo o período, observamos que todas são IES públicas, a saber: USP-SP (213), UFSCar (47), UFMG (39), UNIFESP (20), UFTM (19), UNICAMP (14), UFPR (11), UNESP (11) e USP-RP (10). Dentre estas, somente autores ligados à USP-SP e à UFSCar foram arrolados desde os anos 1990. A Figura 4 se detém sobre as IES de origem dos autores que tiveram um volume maior de trabalhos nos intervalos de período elencados.

Podemos falar em uma importante concentração de autores oriundos da própria USP-SP, o que demonstra uma endogenia de autores da IES que sedia e produz o periódico em todo o período. Todavia, uma inflexão relevante ocorre a partir do intervalo entre 2006-2010, e que permanece até 2014. Por outro lado, nesse mesmo intervalo, se observa o crescimento relativamente regular de autores de três IES (UFSCar, UNIFESP e UFTM) e uma pequena (relativamente) inflexão negativa de autores oriundos da UFMG.

$\mathrm{Na}$ tentativa de compreender melhor esse fenômeno, comparamos a produção das IES com até dez autores e a da USP-SP, separadamente, o que é trazido na Figura 5.

De fato, a inflexão negativa dos autores provenientes da USP-SP se mostrou um fenômeno próprio em relação à forte tendência de aumento das outras IES consideradas, o que, dentre outras possibilidades, pode resultar dos esforços dos editores do periódico em limitar a endogenia presente em todo o período. Entre 2006-2011 e 2011-2014, a participação de autores provenientes da USP-SP baixou de 72 para 35 (uma queda de 48,6\%); já a participação das demais IES foi, conjuntamente, de 38 para 102 (um aumento de $168,4 \%)$.

Entre 1990 e 2014, os autores que publicaram nos Cadernos provinham de 131 diferentes instituições, sendo que não foi possível verificar a procedência de autores de 28 textos. Observa-se a predominância de IES, com 75 instituições, mas também a presença 
de serviços, órgão de gestấo pública, entre outras. Dentre as IES, das 64 nacionais, 33 são públicas e 31 privadas, sendo 11, portanto, as estrangeiras.

Ressalta-se que a diversidade de instituiçôes se modificou bastante no período, com a grande maioria destas passando a publicar, apenas, depois de 2010, e, com grande intensificação, no período 2011-2014, inclusive entre os autores da própria UFSCar, conforme a Figura 6.

As instituiçóes com dez ou mais autores foram: UFSCar (145), USP-SP (33), USP-RP (25), UFPR (22), UNIFESP (19), UFTM (15), UFMG (13), UNESP (13) e UNICAMP (10); destas, apenas as três primeiras tiveram autores que publicaram desde os primeiros cinco anos de existência da revista. A Figura 6 traz a distribuição das instituições dos autores em períodos, priorizando aquelas que tiveram um volume maior de autores.

Novamente, se observa uma concentração de autores oriundos da própria UFSCar, colocando também aqui o problema da endogenia do periódico em relação à sua instituição de vínculo. No intervalo 2006-2010 até 2014, todas as IES consideradas elevaram o número de autores participantes, de forma relativamente semelhante, embora menor para a UFSCar, mas, com uma importante diferença para a USP-SP, que passou de um para 24 autores, um aumento de $2.300 \%$ nesse intervalo. De fato, docentes da USP-SP, anteriormente a 2006-2010, tinham tido apenas oito autorias de trabalhos publicados nos Cadernos. Autores da UFMG, UFPR, UNIFESP e UFTM náo haviam publicado nenhum trabalho antes do mesmo período, devendo ser destacadas as diferenças entre essas IES, no que concerne ao momento em que passaram a contar com cursos de graduação em terapia ocupacional e, portanto, com a própria área de terapia ocupacional.

A Figura 7 traz dados agrupados sobre a participação de IES com pelo menos dez autores e de autores da UFSCar, separadamente.

Verifica-se que, a partir do período 2006-2010, e com forte permanência dessa tendência até 2014, os Cadernos de Terapia Ocupacional da UFSCar se tornaram um veículo muito mais atrativo para as IES que mais produziram na área. Dentre as hipóteses explicativas para esse fenômeno, nos parece relevante a importante mudança dos rumos definidos pelos editores dos Cadernos no mesmo período, principalmente os resultados positivos da busca por sua melhor indexação acadêmica, mudanças na composição do conselho editorial e na política das seçôes e no layout, assim como da disponibilização on-line de todo o seu acervo, dentre outras medidas,

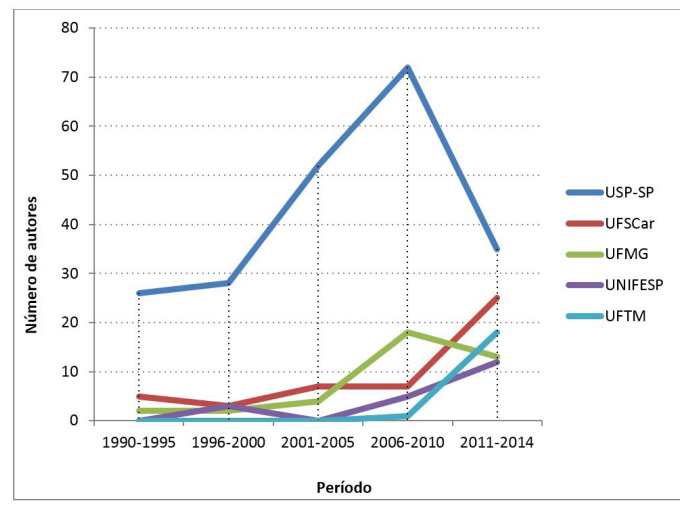

Figura 4. IES de origem dos autores das publicações na Revista de Terapia Ocupacional da USP, 1990-2014. Fonte: Revista de Terapia Ocupacional da USP (1990-2014), elaboração das autoras.

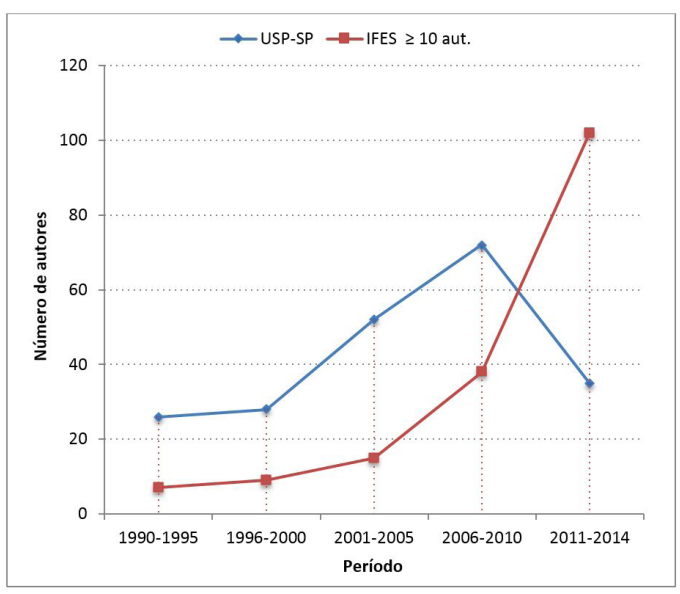

Figura 5. Comparação entre a proporção de IES de origem dos autores das publicações na Revista de Terapia Ocupacional da USP, 1990-2014. Fonte: Revista de Terapia Ocupacional da USP (1990-2014), elaboração das autoras.

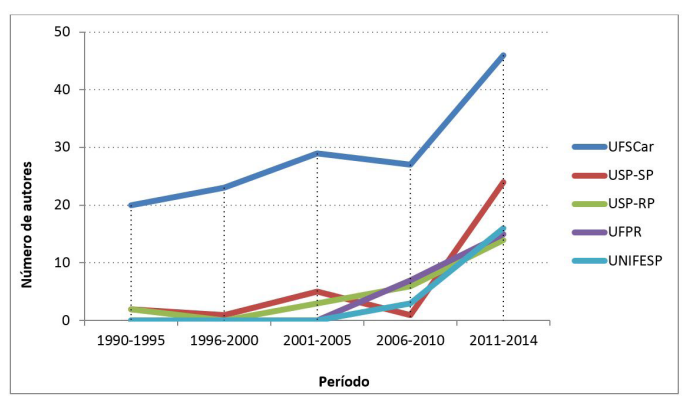

Figura 6. IES de origem dos autores das publicações nos Cadernos de Terapia Ocupacional da UFSCar, 1990-2014. Fonte: Cadernos de Terapia Ocupacional da UFSCar (1990-2014), elaboração das autoras. 


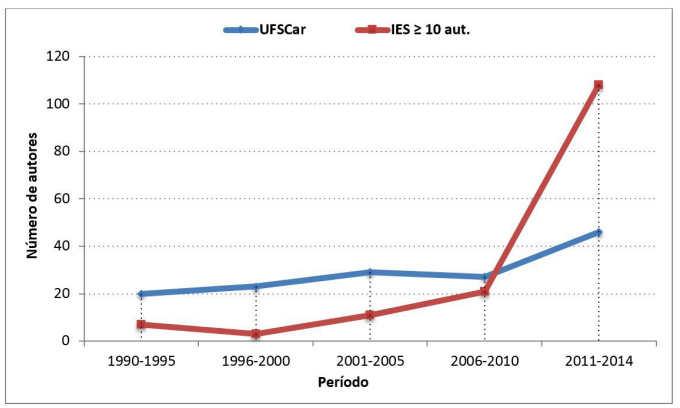

Figura 7. Comparação entre a proporção de IES de origem dos autores das publicações nos Cadernos de Terapia Ocupacional da UFSCar, 1990-2014. Fonte: Cadernos de Terapia Ocupacional da UFSCar (1990-2014), elaboração das autoras.

que decorreram também da proposta, apresentada em 2009 pela área na UFSCar à Coordenação de Aperfeiçoamento de Pessoal de Nível Superior CAPES, de um Programa de Pós-Graduação em Terapia Ocupacional, efetivamente implantado no período 2010-2012.

Pode-se aludir que, talvez, um grupo de autores provenientes de IES com maior tradição em pesquisa passou a considerar relevante divulgar resultados de seus estudos nos Cadernos, o que é especialmente evidenciado no caso de autores filiados à USP-SP.

\subsection{Número de textos por autor/autora}

Outro componente fundamental para que se possam discutir os desafios e os compromissos em torno da produção e da divulgação do conhecimento em terapia ocupacional no país é saber quem vem trabalhando nesse âmbito, ou seja, quem são os autores dos trabalhos publicados nos dois periódicos indexados em bases acadêmicas da área.

Antes de tudo, pontua-se que são autoras e não autores quem publica nesses periódicos, já que dos 725 diferentes autores encontrados nos Cadernos de Terapia Ocupacional da UFSCar, 631 são mulheres (87\%), e dentre os 679 relacionados na Revista de Terapia Ocupacional da USP, 574 são mulheres (84,5\%). Entre essas mulheres - assim como entre os homens -, a absoluta maioria é composta por terapeutas ocupacionais.

A média de publicação por autor(a) é muito próxima entre os dois veículos, sendo 2,48 textos na Revista de Terapia Ocupacional da USP e 2,45 textos nos Cadernos de Terapia Ocupacional da UFSCar, o que demonstra a incipiência da assunção dessa tarefa entre os terapeutas ocupacionais brasileiros, ao menos em relação a esses veículos.

Tomando-se todo o período pesquisado, se considerarmos autores com pelo menos dez trabalhos publicados, teremos 13 autoras na Revista de Terapia Ocupacional da USP (com números de publicaçóes que variam entre 32 e 10), sendo que apenas uma delas não é graduada em terapia ocupacional e apenas uma não era docente da USP-SP. Nos Cadernos de Terapia Ocupacional da UFSCar, são seis autoras (com números que variam entre 14 e dez publicaçóes), todas com graduação na área e unicamente uma delas não sendo docente da UFSCar. Somente uma autora apresenta dez ou mais trabalhos publicados nos dois periódicos.

Quando comparados os autores das duas revistas, do total de 1.404 pessoas, 153 nomes aparecem em ambas, ou seja, apenas 10,9\% dos autores têm divulgado o conhecimento nos Cadernos de Terapia Ocupacional da UFSCar e na Revista de Terapia Ocupacional da USP.

Contudo, o que mais se evidencia como uma questão entre desafios e compromissos é o fato de que em ambos os periódicos mais de 80\% dos(as) autores/autoras publicaram apenas um trabalho e em torno de somente 5,3\% na Revista de Terapia Ocupacional da USP e de 3,2\% nos Cadernos de Terapia Ocupacional da UFSCar publicaram cinco ou mais trabalhos, conforme se pode observar, a seguir, nas Figuras 8 e 9.

Tais dados são extremamente preocupantes com relação à efetiva institucionalização acadêmica da terapia ocupacional no Brasil, pois a existência de trabalhos publicados pela área (artigos de pesquisa, relatos de experiência, artigos de reflexão etc) é condição necessária, mas não suficiente, para o diálogo e a construção acadêmicos

$\mathrm{O}$ fato de haver tantos autores de um único texto demonstra essa falta de diálogo, de debate da produção acadêmica nos termos mais considerados nesse fazer: divulgar resultados da tarefa de produzir conhecimentos, em sua forma escrita.

Não obstante, como já colocado, dado o fato de essa atividade ocorrer notadamente nas IES públicas e de que apenas recentemente a área de terapia ocupacional pôde estar presente nessas instituiçóes em todas as regióes do país, embora ainda não em todos os estados da Federação (PAN; LOPES, 2016), a pergunta que se colocou foi se essa situação teria sido diferente se fossem considerados apenas os últimos dez anos, já que foi a partir de 2004 que começamos a assistir a essa mudança, que se aprofundou entre 2008 e 2010. 
Especificamente no recorte temporal de 2005 a 2014, permanecem as autoras $(86,5 \%)$ e não os autores dentre 629 diferentes nomes encontrados nos Cadernos de Terapia Ocupacional da UFSCar, bem como em relaçáo aos 520 relacionados na Revista de Terapia Ocupacional da USP, com 85,2\% de mulheres. As Figuras 10 e 11, a seguir, permitem a visualização da distribuição dos textos por autor no mesmo período.

A média de publicação por autor/autora também pouco se altera nos dois veículos, sendo 2,8 textos na Revista de Terapia Ocupacional da USP e 2,7 nos Cadernos de Terapia Ocupacional da UFSCar, mantendo-se, portanto, a incipiência da publicação entre os terapeutas ocupacionais nos principais periódicos brasileiros da área.

Com relação aos autores/autoras com pelo menos dez trabalhos publicados, como era de se esperar, esse número baixa para cinco autoras na Revista de Terapia Ocupacional da USP, com número de

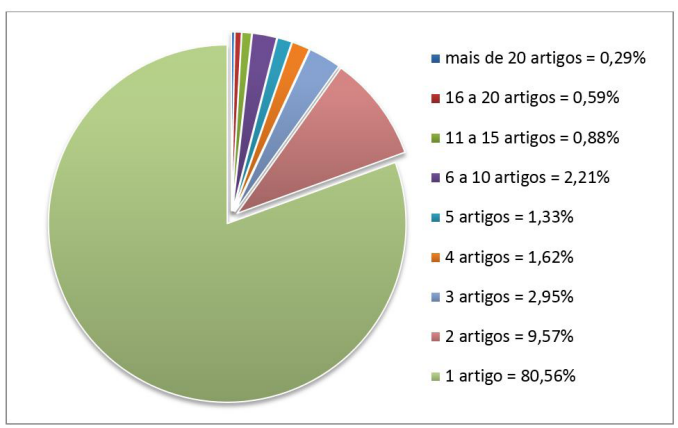

Figura 8. Número de textos publicados por autor/autora na Revista de Terapia Ocupacional da USP, 1990-2014. Fonte: Revista de Terapia Ocupacional da USP (1990-2014), elaboração das autoras.

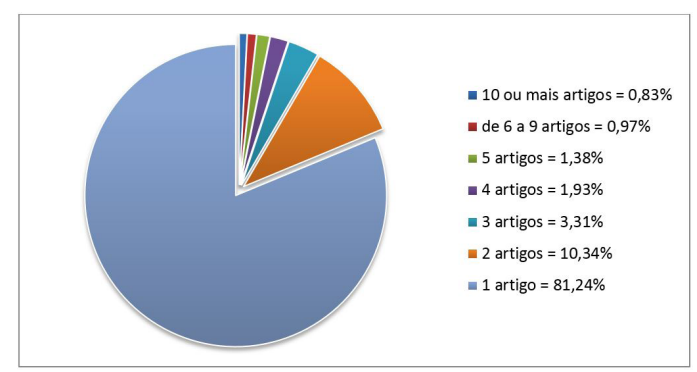

Figura 9. Número de textos publicados por autor/autora nos Cadernos de Terapia Ocupacional da UFSCar, 1990-2014. Fonte: Cadernos de Terapia Ocupacional da UFSCar (1990-2014), elaboração das autoras. publicaçóes que varia entre 21 e 10 , sendo que apenas uma delas não é docente da USP-SP; já nos Cadernos de Terapia Ocupacional da UFSCar, o maior número de publicaçôes por autor/autora foi oito nesse período. A boa notícia é que, se tomarmos cinco e não dez trabalhos, a situação melhora relativamente, uma vez que passam para 26 autoras na Revista de Terapia Ocupacional da USP, de dez diferentes IES, e para nove, nos Cadernos de Terapia Ocupacional da UFSCar, de quatro IES distintas.

Mantém-se igualmente o fato de que em ambos os periódicos mais de $80 \%$ dos autores/autoras publicaram apenas um trabalho e apenas $5 \%$ das autoras na Revista de Terapia Ocupacional da USP e 1,4\% nos Cadernos de Terapia Ocupacional da UFSCar publicaram pelo menos cinco trabalhos.

O diálogo acadêmico na terapia ocupacional brasileira tem sido monocórdico.

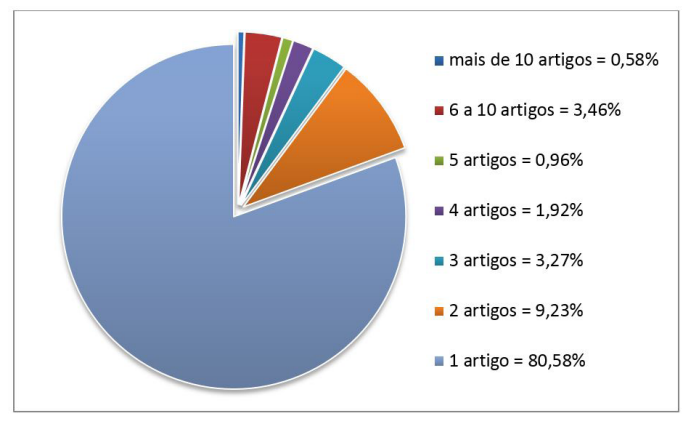

Figura 10. Número de textos publicados por autor/autora na Revista de Terapia Ocupacional da USP, 2005-2014. Fonte: Revista de Terapia Ocupacional da USP (1990-2014), elaboração das autoras.

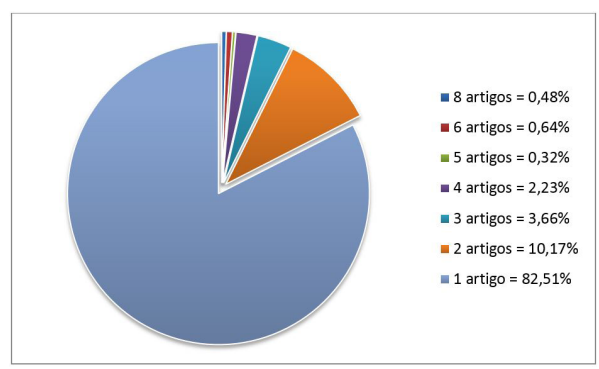

Figura 11. Número de textos publicados por autor/autora nos Cadernos de Terapia Ocupacional da UFSCar, 2005-2014. Fonte: Cadernos de Terapia Ocupacional da UFSCar (1990-2014), elaboração das autoras. 


\section{Conclusão}

Os resultados encontrados pela leitura dos resumos não permitiram a categorização do que se denominou "método/metodologia", como também, dada sua enorme variação e dispersão, não foi possível agrupar satisfatoriamente o uso das palavras-chave nos textos publicados.

No que se refere a "método/metodologia", para além de uma classificação ligeira em abordagens "qualitativas" e/ou "quantitativas", os textos parecem decorrer de trabalhos de pesquisas que pouco se detêm nessa questáo, talvez por permanecer ainda algum estranhamento quanto à sugestão desse formato para os resumos nas normas dos periódicos. Não obstante, nos últimos anos, tem crescido a apresentação de informações sobre método reduzida a certo tipo de classificação do que seriam estudos "exploratórios", "descritivos" ou "transversais", por exemplo, o que, aparentemente, resolveria o "enquadre", mas pouco diz das metodologias empregadas na abordagem dos objetos de pesquisa e, menos ainda, de suas perspectivas de análise. Há que se caminhar quanto a estes aspectos no âmbito da pesquisa em terapia ocupacional no Brasil, começando, muito certamente, pela ampliação de sua produção entre os estudiosos da área. Um dado interessante foi a quase absoluta falta de mençáo a financiamentos dos estudos que poderiam ter subsidiado as publicações. Isto vem sendo pauta constante do Grupo de Trabalho de Pesquisa e Pós-Graduação da RENETO e de eventos da área (LOPES; MALFITANO, 2009; LOPES et al., 2010, 2014).

Quanto a enorme variedade e dispersão dos descritores/palavras-chave utilizados nas publicaçôes, uma explicação possível seria isso decorrer do fato de que a normatização presente na área da saúde - internacionalmente, pelo PUBMED, e na América Latina, pelos Descritores em Ciências da Saúde - pode não abranger toda a área de terapia ocupacional e/ou incorporar de maneira muito restrita as temáticas atinentes à terapia ocupacional, de modo a não representarem suficientemente o interesse dos autores. Nas ciências sociais, debate-se a contribuição ou não da padronizaçáo e das bases de referência, como praticado pela base Sociological Abstract, e não são criadas listagens fixas, como ocorre em boa parte da área da saúde. Ainda, essa dispersão se, por um lado, demonstra que os terapeutas ocupacionais, no histórico dos periódicos, tiveram liberdade para a nomeação dos descritores de seus textos, o que pode ser objeto de estudos futuros acerca da composiçáo do campo, por outro lado, expressa a existência de uma dificuldade de organização/classificação e de maior uniformização das temáticas tratadas por eles.

É importante que se mencione que essas foram dificuldades encontradas por nós e que outros pesquisadores talvez lidassem melhor com essas possíveis categorizaçóes; de todo modo, uma sugestão que pode ser colocada é que seja feito um recorte de estudo sobre os textos mais recentes, especificamente artigos de pesquisa, para se verificar se houve mudança nesses cenários.

$\mathrm{Na}$ experiência de parte das autoras na editoria dos Cadernos de Terapia Ocupacional da UFSCar, desde 2011, quando se pleiteou e se obteve sua indexação na base LILACS, tem se exercido maior cobrança dos autores quanto ao uso das palavras-chave e à apresentação dos resumos.

Este é um ponto a ser destacado na composição dos desafios e compromissos da área frente à divulgação do conhecimento produzido: fazer com que a circulação das produçóes aumente e se dê por caminhos reconhecidos academicamente. Uma importante forma passaria pela indexação dos periódicos em bases de dados relevantes para a terapia ocupacional. Quando somos classificados como área de "saúde", os critérios de tais bases são provenientes, majoritariamente, da área biomédica, tornando ainda mais difícil o enfrentamento destas nuances.

Seria importante a consideração das interfaces da terapia ocupacional com as áreas de ciências humanas e sociais, para a construção dos parâmetros aqui discutidos; nossa hipótese é de que, nesses âmbitos, que nos parecem bastante mais afetos ao rol de temáticas com o qual dialogam os terapeutas ocupacionais, teórica e praticamente, essa construçáo com qualidade seria menos árida e potencializaria aquela circulação e divulgação.

Em síntese, no quadro histórico, é notável que ambas as revistas têm uma produção restrita e incipiente para configurar uma área de conhecimento.

Essa dificuldade vem sendo lidada por parte dos terapeutas ocupacionais, especialmente aqueles ligados às IES, bem como pelas equipes de editoria dos periódicos. A luta pela melhor indexação dos periódicos é uma face desse trabalho que, entretanto, só terá condições de efetivamente florescer quando o acesso dos terapeutas ocupacionais às fontes da produção de conhecimento também se tornar mais favorável do que até hoje nos foram (LOPES et al., 2014). Em parte, esse processo depende de nós.

É necessário que a prática do diálogo acadêmico seja aprofundada por meio dos veículos que até aqui construímos no Brasil. Igualmente, é necessário que 
esse diálogo seja plural e adensado por publicaçóes que demonstrem trajetórias de pesquisa, de conhecimentos construídos, de interesses temáticos persistentes e consolidados, e não apenas a amplitude e, é claro, a riqueza desses interesses.

A dispersão de autores/autoras indica, de um lado, um grupo importante daqueles que tentaram com sucesso tomar a palavra (escrita) nesse diálogo e, por outro lado, uma polifonia que talvez diga da nossa dificuldade em produzir enquadres com os quais efetivamente nos identifiquemos e, a partir dos quais, nos posicionemos na terapia ocupacional e nos lancemos com alguma consistência, academicamente.

Certamente, isto está mais ligado ao que se espera dos docentes e pesquisadores da área e, quanto a isso, uma preocupação é com o número de pessoas que percorreram e continuam percorrendo a carreira docente sem lidar com essa tarefa, que publicam pouco ou simplesmente não publicam, e elas existem também entre nós. Sabemos dos limites de uma visão que vê toda produção acadêmica restrita aos artigos de pesquisa publicados em veículos tidos como mais qualificados e, com esta, não compactuamos. Todavia, esse é um desafio entre nós e precisamos enfrentá-lo da forma que julguemos mais coerente com o que temos defendido para a terapia ocupacional brasileira, sua condição de contribuir para solucionar problemas e necessidades da nossa sociedade.

Nossos periódicos têm sido um dos instrumentos para isso.

\section{Referências}

ARAÚJO, C. A. Bibliometria: evolução histórica e questóes atuais. Em Questão, Porto Alegre, v. 12, n. 1, p.1132, 2006.
CADERNOS DE TERAPIA OCUPACIONAL DA UFSCar. São Carlos: UFSCar, 1990-2014.

EMMEL, M. L. G.; LANCMAN, S. Quem são nossos mestres e doutores? O avanço da capacitaçáo docente em terapia ocupacional no Brasil. Cadernos de Terapia Ocupacional da UFSCar, São Carlos, v. 7, n. 1, p. 29-38, 1998.

LOPES, R. E.; MALFITANO, A. P. S. Perspectivas e desafios para a pesquisa em terapia ocupacional: uma análise do seu I Seminário Nacional de Pesquisa. Cadernos de Terapia Ocupacional da UFSCar, São Carlos, v. 17, p. 115-120, 2009. Suplemento 1.

LOPES, R. E. et al. Pesquisa em terapia ocupacional: apontamentos acerca dos caminhos acadêmicos no cenário nacional. Revista de Terapia Ocupacional da Universidade de São Paulo, São Paulo, v. 21, n. 3, p. 207-214, 2010.

LOPES, R. E. et al. II Seminário Nacional de Pesquisa em Terapia Ocupacional: caminhos para a institucionalização acadêmica da área. Revista de Terapia Ocupacional da Universidade de São Paulo, São Paulo, v. 25, n. 2, p. 167-176, 2014.

MALFITANO, A. P. S. et al. Programa de pós-graduação stricto sensu em terapia ocupacional: fortalecimento e expansão da produçáo de conhecimento na área. Revista Brasileira de Atividade Física e Saúde, Pelotas, v. 18, n. 1, p. 105-111, 2013.

PAN, L. C.; LOPES, R. E. Políticas de ensino superior e a graduaçáo em terapia ocupacional nas Instituiçốes Federais de Ensino Superior no Brasil. Cadernos de Terapia Ocupacional da UFSCar, São Carlos, v. 24, n. 3, p. 457-486, 2016.

REVISTA DE TERAPIA OCUPACIONAL DA USP. São Paulo: USP, 1990-2014.

\section{Contribuições dos Autores}

Todas as autoras participaram da elaboraçáo da proposta de pesquisa. Maria Luiza Mangino Cardoso Duarte e Beatriz Prado Pereira foram responsáveis pela coleta e organizaçáo inicial dos dados, que foram analisados e discutidos conjuntamente pela equipe de trabalho. Roseli Esquerdo Lopes foi responsável pela elaboração do texto, que foi revisado por todas as autoras. Todas as autoras aprovaram a versão final do texto.

\section{Fonte de Financiamento}

Auxílio Pesquisa - CNPq, Processo No 477027/2013-0.

\section{Notas}

${ }^{1}$ Assinala-se que o trabalho realizado não se moldou pelas proposições de um estudo bibliométrico (ARAÚJO, 2006), algo que estaria fora do escopo de competências das autoras.

2 Até 2002, sob o ISSN 1415-9104, disponíveis apenas em formato impresso e, em 2008, disponíveis no formato eletrônico (on-line), sob o ISSN 2238-6149. 
${ }^{3}$ Com volumes impressos desde 1990, sob o ISSN 0104-4931, e a partir de 2011, sob o ISSN 2238-2860, também no formato eletrônico (on-line), sendo que todos os volumes até o final de 2014 estavam disponíveis em ambos os formatos.

${ }^{4}$ Foram considerados textos quaisquer materiais publicados, em qualquer categoria de classificação utilizada pelos periódicos.

${ }^{5} \mathrm{Na}$ Revista de Terapia Ocupacional da USP dois suplementos em CD-ROM, um em 2008 e outro em 2011, trouxeram os anais do XI Encontro Nacional de Docentes de Terapia Ocupacional (ENDTO) e do VI Encontro Latino-Americano de Escolas e Docentes de Terapia Ocupacional, respectivamente. Os Cadernos de Terapia Ocupacional da UFSCar publicaram, no período, um suplemento especial do seu vol. 17, no. 1, em 2009, disponível no formato impresso e eletrônico, trazendo os anais do I Seminário Nacional de Pesquisa em Terapia Ocupacional (SNPTO), e outros três em 2010, 2012 e 2014 , apenas em CD-ROM, com os anais dos eventos XII ENDTO, XIII ENDTO e II SNPTO, XIV ENDTO e III SNPTO, respectivamente. Ainda, publicou, como suplemento especial, os anais dos seguintes eventos profissionais da área: XII Congresso Brasileiro de Terapia Ocupacional (CBTO) e IX Congresso Latino-americano de Terapia Ocupacional (CLATO), em 2011, XIII CBTO, em 2013, e X Congresso Norte-Nordeste de Terapia Ocupacional (CONNTO), em 2014.

${ }^{6}$ Terapêutico-ocupacional; terapêutica ocupacional, terapeuta(s) ocupacional(ais).

${ }^{7}$ Em 2015, a Revista de Terapia Ocupacional da USP tinha, como fontes de indexação: - Sistema Regional de Información en Línea para Revistas Científicas de América Latina, el Caribe, España y Portugal - LATINDEX; - Literatura Latinoamericana e do Caribe em Ciências da Saúde - LILACS; - Periódica; - DOAJ - Directory of Open Access; - Journals; - CAPES e - EBSCO Publishing.

${ }^{8}$ Em 2015, os Cadernos de Terapia Ocupacional da UFSCar referiam como indexação: Literatura Latino-americana e do Caribe em Ciências da Saúde - LILACS; - CINAHL - EBSCO; - ProQuest-Social Services Abstracts; - ProQuest-Nursing \& Allied Health Source database; - CUIDEN; Sistema Regional de Información en Línea para Revistas Científicas de América Latina, el Caribe, Espańa y Portugal - LATINDEX; Occupational Therapy Journal Literature Search Service - OTDATABASE; Periódica; - DOAJ - Directory of Open Access Journals; - Portal de Periódicos da CAPES, e - Ulrich's International Periodical Directory. 